\title{
Três articulações da publicidade com o mundo social
}

\author{
Marinês Andrea Kunz \\ Universidade Feevale
}

João Batista Nascimento dos Santos

Universidade Federal do Rio Grande do Sul

\begin{abstract}
Resumo
Este artigo, entende a publicidade como uma importante forma de comunicação para a sociedade contemporânea e tem por objetivo refletir sobre ela a partir de três pontos de vista, sendo o primeiro o que considera a conexão entre a publicidade e as relações de produção; o outro, que analisa o consumo e a publicidade com base na ética; e, ainda, a noção que busca a compreensão da publicidade no seu papel de contribuir na construção do imaginário contemporâneo, notadamente, considerandose o aspecto de sugestionar a construção das identidades e subjetividades dos sujeitos. Já há algum tempo, a publicidade pôs em movimento um processo de recomposição das representações sociais em suas campanhas, embora em grande parte das produções comerciais permaneça uma abordagem com base em um padrão hegemônico na representação do corpo. Há relevância em estudar esta reelaboração, para engendrar uma compreensão sobre a lógica das representações do corpo na publicidade, buscando depreender os vínculos criados com a cultura que colaboram para que a publicidade tenha esse caráter.
\end{abstract}

\section{Palavras-chave:}

Publicidade. Corpo. Identidade. Cultura. Subjetividade.

\section{A Publicidade}

A publicidade é uma forma de comunicação relacionada à questão das relações de produção, bem como com o consumo dos mais diferentes produtos e serviços. Contudo, importante também considerar que a publicidade está igualmente vinculada à cultura, pelo aspecto de o texto publicitário representar o cotidiano e, desse modo, colaborar para engendrar a realidade e, consequentemente, influenciar no modo de vida dos sujeitos. Além disso, essa mesma publicidade que influencia a cultura também acaba por ser sugestionada por essa mesma cultura, em um processo de retroalimentação.

A publicidade é um processo de comunicação de grande importância para as sociedades capitalistas. Conforme Williams (2011), a propagação de informação por um anunciador ou por meio de cartazes foi algo recorrente em todos os períodos da

Revista Ícone (ISSN 2175-215X) • DOI: 10.34176/icone.v17i2.239076

Recife, Vol. 17, N. 2, 158-171, ( 2019 PPGCOM/UFPE.

Artigo recebido em 30 nov. 2018 e aprovado em 5 mai. 2019.

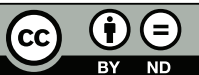


sociedade inglesa. Entre as décadas de 1880 e 1890, começou a surgir o que Williams (2011) define como nova publicidade, a qual surgiu em razão do novo capitalismo monopolista corporativo. O período entre 1875 e 1890 foi marcado por uma grande depressão, fator decisivo para a mudança no modo de organização empresarial. Passada a depressão e a grande redução nos preços, havia receios relativos à capacidade produtiva. Além disso, a propriedade industrial encaminhou-se para uma organização em grandes unidades e conglomerados, buscou organizar-se e, quando possível, alcançar o controle do mercado. Para realizar esses objetivos, a publicidade foi um dos recursos utilizados para divulgar uma quantidade cada vez maior de produtos.

A publicidade moderna pertence, poderíamos dizer, ao sistema de controle de mercado que, em seu desenvolvimento pleno, inclui o aumento de tarifas e de áreas privilegiadas, cotas de cartéis, campanhas comerciais, pré-fixação de preços pelos produtores e aquela forma de imperialismo econômico que assegurou alguns mercados por meio do controle político do território. (WILLIAMS, 2011, p. 242).

A publicidade passou a ser vista de uma forma muito mais atraente pelos proprietários dos veículos de comunicação, como modo interessante para o financiamento de suas empresas. Passou, assim, a ter o caráter de profissão, serviço público e parte importante da economia.

O meio século entre 1880 e 1930, então, viu o desenvolvimento pleno de um sistema de um sistema organizado de informação e persuasão comercial como parte de um sistema moderno de distribuição nas condições do capitalismo em larga escala. (WILLIAMS, 2011, p.244).

Atualmente, vivemos uma fase em que os bens de consumo são rapidamente distribuídos. A razão para a busca por um número cada vez maior de produtos e serviços para satisfazer as necessidades humanas está no incentivo ao consumo gerado pela publicidade.

A publicidade moderna pertence, poderíamos dizer, ao sistema de controle de mercado que, em seu desenvolvimento pleno, inclui o aumento de tarifas e de áreas privilegiadas, cotas de cartéis, campanhas comerciais, pré-fixação de preços pelos produtores e aquela forma de imperialismo econômico que assegurou alguns mercados por meio do controle político do território (WILLIAMS, 2011, p. 242). O meio século entre 1880 e 1930, então, viu o desenvolvimento pleno de um sistema organizado de informação e persuasão comercial como parte de um sistema moderno de distribuição nas condições do capitalismo em larga escala (WILLIAMS, 2011, p.244).

A publicidade é uma forma de comunicação complexa, que envolve aspectos econômicos, sociais e culturais e, em meio a isso tudo, o consumo é questão fundamen- 
tal. Ao longo de sua história, a humanidade tem realizado atividades de consumo ou análogas a essa prática, o que inclui a produção, o armazenamento, a distribuição e a remoção de objetos de consumo. Tais atividades têm mantido de modo constante o suprimento com matéria-prima, a qual serviu de suporte para o engendramento de várias formas de vida e padrões de relação inter-humanas (BAUMAN, 2008). A revolução paleolítica findou a forma de vida precária dos povos coletores, dando início ao período dos excedentes e das estocagens. Entretanto, Bauman (2008) argumenta que a ruptura com essas formas de vida ocorre com a revolução consumista, a qual teve lugar milênios à frente, quando o consumo transformou-se em consumismo, fenômeno que acabou se tornando central na vida de muitas pessoas. Citando Colin Campbell, o teórico completa que o consumismo se transformou em algo muito importante, primordial na vida de muitos indivíduos, "o verdadeiro propósito da existência". "E quando nossa capacidade de 'querer,' 'desejar', 'ansiar por' e particularmente de experimentar tais emoções repetidas vezes de fato passou a sustentar a economia do convívio humano" (BAUMAN 2008, p.38).

A relação que é estabelecida entre as pessoas e os objetos disponibilizados para o consumo não é algo simples e direta, pois, conforme Williams (2011), a publicidade demonstra que os objetos oferecidos nunca se bastam para o atual padrão cultural. Eles precisam ser legitimados, mesmo que fantasiosamente, através de associações com significados sociais e pessoais. Sobre esse aspecto, Baudrillard (2000) argumenta que função da publicidade seria informar as características dos produtos ou serviços e impulsionar sua venda, função objetiva que seria supostamente a principal. Posteriormente, a publicidade, que estava voltada para informação, passou a fazer uso da persuasão e, mais à frente, a persuasão clandestina. Baudrillard esclarece que o objetivo da publicidade, nesta última forma, seria estabelecer um consumo dirigido.

A partir dos estudos realizados sobre a publicidade, observou-se que a possibilidade de uma assimilação total do conteúdo publicitário não ocorre. Existiria uma espécie de reação por saturação, ou seja, os vários anúncios acabariam por se neutralizarem uns aos outros ou, ainda, cada um por seus excessos. Por outro lado, a injunção e a persuasão fazem surgir vários tipos de contramotivações e de resistências, sejam elas racionais ou irracionais, tais como reação a passividade ou a repetição do discurso, além de outras respostas. $\mathrm{O}$ que se entende é que o discurso publicitário simultaneamente dissuade e persuade, o que dá a noção de que os indivíduos teriam bastante discernimento acerca das mensagens publicitárias. Nesse sentido, a função explícita da publicidade não geraria persuasão no consumidor. A função explícita da publicidade não realiza a persuasão dos indivíduos relativa a determinadas marcas de produtos, pois essa persuasão funciona para algo mais relevante para a ordem da sociedade.

Embora exista resistência ao imperativo publicitário, o inverso disso é que acabamos sendo mais suscetíveis ao indicativo da publicidade,

ou seja, à sua própria existência como segundo produto de consumo e evidência de uma cultura. É nessa medida que acreditamos nela; o que nela consumimos é o luxo de uma socie- 
dade que se dá a ver como instância distribuidora de bens e que se "ultrapassa" numa cultura. Recebemos ao mesmo tempo uma instância e sua imagem. (BAUDRILLARD, 2000, p. 292).

A lógica da eficácia da publicidade é correspondente à lógica da fábula e da adesão. A apresentação do produto, segundo o teórico, não geraria persuasão, funcionando, sim, na racionalização da compra, a qual precede ou ultrapassa os motivos racionais.

Embora seja oculta, a persuasão da publicidade não objetiva em maior grau a compra de modo compulsivo e o condicionamento aos objetos, o objetivo maior da publicidade é que os indivíduos venham a aderir ao consenso social proposto pelo discurso publicitário:

o objeto é um serviço, é uma relação pessoal entre você e a sociedade. Que a publicidade se organize a partir da imagem maternal ou a partir da função lúdica, de qualquer modo ela visa a um mesmo processo de regressão aquém dos processos sociais reais de trabalho, de produção, de mercado e de valor, que poderiam perturbar esta miraculosa integração: esse objeto, o senhor não o comprou, o senhor sim emitiu o seu desejo e todos os engenheiros, técnicos etc. com ele o gratificaram. (BAUDRILLARD, 2000, p. 294).

A divisão do trabalho desagrega o trabalho do seu produto na sociedade industrial, e a publicidade enfatiza esse processo, realizando a sua dissociação de modo contundente.

No momento da compra, o produto do bem de consumo: intercalando entre o trabalho e o produto do trabalho uma vasta imagem maternal faz com que o produto não seja mais considerado como tal (com sua história etc.), mas pura e simplesmente como bem, como objeto" (BAUDRILLARD, 2000, p. 294).

O teórico é corroborado por Rocha (1995), que afirma que a publicidade se situa entre dois domínios importantes do circuito econômico, que são as esferas da produção e do consumo. Por meio da atribuição de identidade aos produtos, ela os particulariza, dando-lhes uma nova existência em que as relações de produção deixam de ser ostensivas. A partir do anúncio, o produto passa a viver em meio a relações simbólicas e sociais características do consumo.

Junto a um mesmo indivíduo, a publicidade pode, simultaneamente, realizar a dissociação entre produtor e consumidor, sustentada na abstração material de um sistema muito diferenciado de objetos e concomitantemente a publicidade busca, numa perspectiva contrária, a reelaboração de uma confusão infantil entre o objeto e o desejo do objeto criando a possibilidade de que o consumidor regresse em uma fase que se 
assemelha à posição de uma criança que não consegue discernir sua mãe do que ela lhe dá (BAUDRILLARD, 2000).

A sugestão da publicidade de que a sociedade se adaptaria aos indivíduos e, em contrapartida, estes teriam que se integrar totalmente a ela é algo que não se concretiza na reciprocidade, pois é uma instância imaginária que se adapta aos indivíduos, os quais teriam que se adaptar a uma ordem real. A sociedade assume um caráter maternal para salvaguardar a ordem de coerção. Nesse aspecto, pode-se refletir sobre o papel político exercido pela propagação de produtos e as técnicas publicitárias, as quais asseveram a substituição das ideologias anteriores, morais e políticas. $\mathrm{O}$ consumidor assimila, no próprio ato do consumo, a instância social e suas normas. $\mathrm{O}$ estatuto do signo publicitário e sua leitura dão mais vigor a essa eficácia.

Não nos é apresentada uma explicação sobre os objetos, pois os signos publicitários somente falam destes. Tais signos referem-se aos objetos reais enquanto mundo ausente e cumprem a função de prova de ausência do que designam. "Nessa medida, a leitura, não transitiva, organiza-se em um sistema específico de satisfação, no qual, entretanto, aparece sem cessar a determinação de ausência do real: a frustração. A imagem cria um vazio, visa a uma ausência. Por isso é 'evocadora"' (BAUDRILLARD, 2000, p295).

Aos indivíduos, a publicidade não propõe uma satisfação alucinatória ou mesmo uma mediação prática com a vida, o que propõe é a veleidade enganada, uma aurora de objetos e desejos. Um psicodrama é desenvolvido ao ler as imagens, pois, inicialmente, possibilita ao leitor a assunção da passividade e a sua conversão em consumidor, uma vez que a torrente de imagens está voltada, simultaneamente, a suprimir a conversão para o real, para suprir tenuemente a culpabilidade por uma frustração contínua, para obstar a consciência por intermédio de uma satisfação sonhadora. A imagem e sua percepção não são o atalho para o objeto, mas sim a ligação para outra imagem. Além de ocultar as relações de produção, conforme apontado por Baudrillard (2000), na sociedade de consumidores, de acordo com Bauman (2008), a publicidade seria parte da lógica voltada à manutenção dos valores da sociedade de consumidores.

Nessa sociedade voltada para o consumo, a publicidade tem a capacidade de fazer referência às várias preocupações e aos estímulos sustentados pela sociedade de consumidores. As preocupações comuns na sociedade atual são comentadas por Bauman (2008) da seguinte forma:

"estar e permanecer à frente" (à frente da tendência de estilo - ou seja, no grupo de referência, dos "pares", dos "outros que contam", e cuja aprovação ou rejeição traça a linha entre o sucesso e o fracasso. Nas palavras de Michel Maffesoli, "sou o que sou porque outros me reconhecem como tal", enquanto "a vida social empírica não é senão uma expressão de sentimentos de pertenças sucessivas" - a alternativa sendo uma sucessão de rejeições ou uma exclusão final como penalidade pelo fracasso em abrir caminho para o reconhecimento, seja por meio da for- 
ça, argumentação ou artimanhas. (BAUMAN, 2008, p.38).

Neste ambiente onde a publicidade trabalha para incentivar o consumo cada vez mais elevado de bens e serviços e onde a efemeridade desses produtos é cada vez maior, os laços humanos têm propensão a serem orientados e mediados por meio dos mercados de bens de consumo. Assim, o sentimento de pertença não é alcançado por meio de procedimentos administrados e supervisionados através dessas tendências de estilo, tão almejadas pelas pessoas. Tal sentimento de pertença é alcançado por intermédio da própria identificação metonímica do aspirante com a tendência. Existe, pois, a busca pelo processo de autodentificação, e o que resulta disso é ostentado com o amparo "de "marcas de pertença" visíveis, em geral encontráveis nas lojas" (BAUMAN, 2008, p.108).

O teórico cita Maffesoli, para relacionar o termo cunhado por este autor, tribos pós-modernas, com a definição criada por ele, tendências de estilo da sociedade de consumo, como figuras emblemáticas com marcas visíveis, entendidas estas últimas como indicações que fazem a proposição de códigos de vestuário e/ou conduta e que assumem o lugar dos totens ${ }^{1}$ das tribos originais. $O$ valor das marcas de diferentes produtos, para a sociedade atual, se reflete na noção de estar à frente, carregando os emblemas das figuras emblemáticas da tendência de estilo, tão almejados socialmente, proporcionando o reconhecimento e a aceitação ambicionados. Como exemplo, pode-se citar os smartphones, tabletes e computadores da Apple com sua legião de fãs, capazes de permanecer por horas em uma fila para serem os primeiros proprietários da última novidade colocada no mercado pela empresa. Contudo, além das perspectivas apontadas por Bauman (2008) e Baudrillard (2000), a publicidade pode ser refletida em uma perspectiva que procura compreender sua relação com as transformações culturais.

Nesse sentido, o texto publicitário pode ser entendido como documento representativo em parte da produção cultural, pois o discurso publicitário apresenta o cotidiano e também ajuda a construir a realidade e, consequentemente, influencia a percepção da diferença, das identidades, do outro (TRINDADE, 2012).

\section{Identidade e Publicidade}

No âmbito da comunicação, a publicidade é um gênero discursivo que tem como principal função proporcionar ao público informações sobre mercadorias, de modo sedutor e persuasivo. Enquanto universo discursivo, a publicidade desenvolve relações com outros textos de outros universos de discurso da sociedade (TRINDADE, 2012).

A forma como a publicidade constrói a representação, estabelecendo relações entre o mundo tangível e o intangível, favorece a ilusão de que as realidades intangíveis podem ser vividas por meio do consumo. Sendo assim, conforme Williams (2011), a

1 O totem, em seu significado etimológico, é o animal ou a planta que vem a ser escolhido enquanto protetor e guia. O termo faz referência a um povo indígena do Sul do Canadá e significa guardião pessoal ou poder tutelar próprio de um indivíduo 
publicidade necessita de um tipo de análise ampla para sua compreensão, um estudo que considere fatores econômicos, sociais e culturais. Ela necessita ser abordada como uma forma significativa da comunicação social moderna.

A publicidade divulga produtos e serviços, a fim de fomentar vendas e, com isso, ajuda a impulsionar o modo de produção capitalista. Em meio a tudo isso, contudo, é necessário também considerar que a publicidade apresenta uma dimensão cultural, a qual engendra representações sociais que colaboram com a atualização do imaginário contemporâneo (PIEDRAS, 2009). Assim, por construir representações sociais que interferem no imaginário do sujeito, a publicidade também repercutirá na formação das suas subjetividades e identidades.

Identidade e subjetividade são questões inter-relacionadas e fundamentais para entender a relação dos indivíduos com seus corpos e a apropriação dessas questões nos textos publicitários. Woodward (2012) observa que o uso dos termos identidade e subjetividade é intercambiável em algumas situações, havendo realmente uma grande sobreposição entre eles. A subjetividade seria relativa à compreensão que construímos sobre o nosso eu, o que, nesse sentido, está relacionado aos pensamentos e às emoções, sendo estas conscientes ou inconscientes, integrando nossas concepções acerca de quem nós somos. A subjetividade abrange nossos sentimentos e pensamentos mais pessoais, porém, é preciso considerar que nossa subjetividade é vivida em um ambiente social e, neste, a linguagem e a cultura conferem significado à experiência que possuímos de nós mesmos. Nesse ambiente social, assumimos uma identidade. A eficácia dos conjuntos de significados engendrados pelos discursos está na capacidade de nos conquistar como sujeitos. "Os sujeitos são, assim, sujeitados ao discurso e devem, eles próprios, assumi-lo como indivíduos que, dessa forma, se posicionam a si próprios. As posições que assumimos e com as quais nos identificamos constituem nossas identidades" (WOODWARD, 2012 p.55). As dimensões inconscientes do eu são abarcadas pela subjetividade, cuja consequência é a presença de contradições; além disso, a subjetividade pode ser tanto racional quanto irracional. Com o conceito de subjetividade, é possível analisar os sentimentos implicados no processo de produção da identidade, bem como do investimento pessoal em determinadas posições de identidade. Este conceito possibilita elucidar os motivos da adesão a determinadas identidades.

Na perspectiva do Iluminismo, o termo universal está relacionado à determinada qualidade da natureza humana. A questão central para os pensadores dos séculos XVII e XVIII era o homem, sendo uma categoria transcendente e abstrata. Esse é um momento inaugural, pois ocorre aí a disjunção do humano em relação à animalidade, momento em que a universalidade é colocada de modo inquestionável. Os iluministas tinham conhecimento acerca da diversidade das culturas e dos povos, mas o interesse pelo diverso é limitado, pois sua perspectiva é o tema da universalidade do homem. "A diversidade traduz sua unidade; apesar das diferentes raças, costumes, crenças religiosas, a miríade de povos comunga as virtudes de um único gênero (iluminado pelos fílosofos)" (ORTIZ, 2015, p.15). Tudo isso constrói um entendimento universal sobre o homem, o que conduz a generalizações sobre um coletivo diverso, mas que filosofi- 
camente é concebido como homogêneo.

A antropologia entende que o conceito de diversidade está bastante ligado à noção do outro. No final do século XIX, antropólogos, voltados para o que definiam como sociedades primitivas, tinham a intenção de vir a entender um tipo de organização social muito diferente da que tinham conhecimento. Os estudos antropológicos esclareceram que os grupos indígenas são contrastantes à sociedade industrial e que cada um destes forma cultura e identidades próprias. Desde a fundação da disciplina, noções sobre o relativismo cultural se fazem presentes nas discussões. A antropologia é marcada por uma concepção que considera o valor da singularidade de cada cultura. "Os povos dispersos no planeta constituem assim, uma série diversificada na qual cada traço possui características intrínsecas e irredutíveis. A diversidade cultural se exprime pela presença de sociedades justapostas no espaço" (ORTIZ, 2015, p.22).

Já no século XX, começa a surgir um novo entendimento sobre o sujeito, em uma perspectiva que revê a condição deste como entidade única e estável, conduziu a uma nova percepção da identidade como construção negociada por meio da relação do sujeito com os outros, através de um processo de definição e redefinição dos seus contornos. Nesse sentido, observa Silveirinha (2009), os grupos minoritários lutam para constituir-se no espaço público democrático sustentados em suas reivindicações políticas, considerando suas diferenças e sua representação nos diferentes segmentos da sociedade. No enfrentamento da hegemonia entre as possibilidades políticas da atualidade, argumenta Barbalho (2009), as situações em que são estabelecidos contatos, intercâmbios e que marcam a atuação política, além de sindicatos, associações, ONGS e ações como greves, passeatas, manifestações, o espaço da mídia também deve ser parte do fazer político.

Atualmente, a mídia tem autonomia e faz a mediação dos vários campos sociais. Nesse sentido, para que discussões favoráveis ao reconhecimento alcancem ampla parcela da sociedade, é necessário que estas sejam abordadas pelos meios de comunicação. E considerando-se que a identidade se origina do caráter dialógico da interação entre as pessoas, os meios de comunicação são fundamentais para a constituição e o reconhecimento das diferenças (BARBALHO, 2009).

A abordagem da diversidade de corpos na publicidade fundamenta-se também no entendimento dos diferentes grupos sociais que passam a ser considerados a partir das transformações trazidas pela modernidade tardia ou, ainda, pela pós-modernidade, configurando-se esta diversidade como uma questão de identidade. Nesse sentido, é necessário refletir sobre identidade e cultura.

O processo de engendramento de significado a partir de atributos culturais que tenham predominância em relação a outras fontes de significado é designado identidade, sendo que esta também é definida como a origem de significado e experiência de um povo (CASTELLS, 2001). Conforme Denys Cuche (1999), a identidade leva a uma norma de vinculação que precisa ser consciente, fundamentada em oposições simbólicas, anteriormente à identidade cultural se situa o ponto mais amplo que é a identidade social, da qual ela faz parte. "A identidade social de um indivíduo se caracteriza pelo conjunto de suas vinculações em um sistema social: vinculação a uma 
classe sexual, a uma classe de idade, a uma classe social, a uma nação, etc." (CUCHE, 1999, p. 177). Um indivíduo se situa e é situado socialmente em um sistema social em função da identidade, embora a identidade social não se refira somente aos indivíduos, pois todo grupo possui uma identidade que tem correspondência com a sua definição social, sendo que essa possibilita designar o seu lugar no conjunto social.

A diferença é uma singularidade das sociedades da modernidade tardia. Divisões e antagonismos sociais permeiam-nas. Distintas posições de sujeito, ou seja, identidades, para os indivíduos, originam-se nas divergências sociais e nas divisões que perpassam pela sociedade, e estas, embora com tais diferenças, não se desintegram no seu todo, não em função de sua unificação, mas motivadas pela possível articulação conjunta de seus diferentes elementos e identidades, em determinadas situações (HALL, 2001). Embora se caracterize por ser parcial, esta articulação faz com que a estrutura da identidade se mantenha aberta.

As identidades estáveis do passado são desarticuladas pelo deslocamento que também possibilita o surgimento de novas articulações, ou seja, o engendramento de novas identidades, e possibilita que se originem novos sujeitos. As crises globais de identidade (WOODWARD, 2014) estão relacionadas com o que Ernesto Laclau denominou deslocamento, de modo que as sociedades modernas não possuiriam nenhum núcleo ou centro definido que gere identidades fixas, o que existiriam, então, seriam vários centros.

Quando alguém diz que possui determinada identidade, como, por exemplo, "sou jovem, branco ou heterossexual", estas asserções são simultaneamente negações de outras identidades ou diferenças. Oculto nessas afirmações, pode-se entender as seguintes ideias: não sou velho, não sou negro, não sou homossexual. Na perspectiva dos Estudos Culturais, observa Tomaz Tadeu da Silva (2014), a gramática possibilita unicamente dizer "sou jovem", mas ao mesmo tempo está também oculta. Exposições sobre a diferença só fazem sentido relacionadas às colocações sobre a identidade. Nesse sentido, identidade e diferença são sempre interdependentes. Comumente, pensamos a diferença como algo que provém da identidade; assim, a identidade é a referência, sendo o ponto de origem concernente por meio do qual vem a ser determinada a diferença, o que leva a entender que o que somos é a norma, e é por meio dela que descrevemos e emitimos juízo de valor sobre aquilo que não somos.

No encaminhamento que dá a sua reflexão, Silva (2014) entende que identidade e diferença seriam reciprocamente determinadas. Ele argumenta que, diferente da primeira abordagem, a diferença estaria em primeiro lugar. A diferença seria, então, não o resultado do processo, mas o próprio processo através do qual identidade e diferença são produzidas. Ambas são interdependentes e são consequência de atos de criação linguística, ou seja, não têm origem natural e precisam ser ativamente produzidas, sendo criações sociais e culturais. Elas precisam ser nomeadas, portanto, precisam ser construídas por meio da fala.

Por serem, a identidade e a diferença, em parte determinadas por meio da linguagem, a indeterminação e a instabilidade acabam por ser aspectos inerentes a elas, as quais apresentam tanta indeterminação e instabilidade quanto a linguagem da qual 
dependem.

Elas têm origem em um processo de produção simbólica e discursiva, são uma relação social, isto é, sua definição discursiva e linguística acaba por se submeter a diferentes forças e relações de poder. Assim, não são definidas, mas impostas e não se relacionam de modo harmônico; ao contrário, são disputadas. Uma disputa ampla se estabelece na luta pela identidade, pois estão envolvidos aí também outros recursos simbólicos e materiais da sociedade. A afirmação da identidade e a enunciação da diferença revelam a intenção dos distintos grupos sociais assimetricamente situados de assegurar o acesso privilegiado aos bens sociais. Assim, relações de poder permeiam a identidade e a diferença.

O poder se faz presente na diferenciação, processo central que gera a identidade e a diferença.

Há, entretanto, uma série de outros processos que traduzem essa diferenciação ou que com ela guardam uma estreita relação. São outras tantas marcas da presença do poder: incluir/ excluir ("estes pertencem, aqueles não"); demarcar fronteiras ("nós" e"eles"); classificar ("bons e maus";"puros e impuros") [...]. (SILVA, 2014, p. 81).

Inclusão e exclusão sempre fazem parte da afirmação da identidade e da indicação da diferença. Com a afirmação da identidade, são demarcados limites entre o que está dentro e o que está fora, separando "nós" e "eles". A divisão do mundo social entre "nós" e "eles" é relacionada à classificação, sendo o processo de classificação central na vida social. Este processo seria um ato de significação por meio do qual é realizada a divisão e o ordenamento do mundo social em grupos e classes. O modo como a sociedade constrói e faz uso de classificações está muito relacionado à identidade e à diferença, pois as classificações são realizadas a partir da perspectiva da identidade. $\mathrm{E}$ essa divisão e classificação levam também à hierarquização. Quem está habilitado a classificar também pode atribuir distintos valores aos que são classificados.

Entre as formas de classificação, a mais relevante é a estruturada a partir de oposições binárias, tendo por referência duas classes polarizadas. Silva (2014) argumenta que as oposições binárias não demonstram uma simples divisão do mundo em grupos simétricos, pois, em uma oposição binária, um dos termos terá permanentemente privilégios, sendo-lhe auferidos valores positivos e para o outro, negativos. Uma oposição binária comum pode ser percebida em "nós" e "eles".

As relações de identidade e diferença ordenam-se, todas, em torno de oposições binárias: masculino/feminino, branco/negro, heterossexual/homossexual. Questionar a identidade e a diferença como relações de poder significa problematizar os binarismos em torno dos quais elas se organizam. (SILVA, 2014, p.83). 
O estabelecimento de uma identidade como sendo a norma é um modo privilegiado de hierarquizar as identidades e as diferenças. Pela normalização, é determinada de modo arbitrário uma identidade como padrão em relação à qual as outras identidades são avaliadas e hierarquizadas. Nesse sentido, na publicidade, a normalização estabelece como identidade padrão um tipo hegemônico de corpo para ser apresentado nos comerciais, o qual é branco, magro, jovem e heterossexual.

Já há algum tempo, são produzidos instrumentos por parte dos campos da publicidade e do marketing, voltados para compreensão e a influência acerca da relação entre os indivíduos e os produtos no que concerne a "imagens do eu, de seu mundo interior, de seu estilo de vida e, sobretudo de seu involucro corporal" (SANTAELLA, p. 126, 2004). As representações nos meios de comunicação e na publicidade produzem um grande efeito relativo às experiências do corpo. Tais representações tornam possível que se imagine, diagrame e se fantasie sobre certas existências corporais, manifestações que se apresentam no modo de sonhar e ambicionar o que é proposto. É estabelecida uma forma de economia psíquica da autoestima e do reforço do poder pessoal sustentada por meio das imagens do corpo e de sua boa forma. Não existindo nesse sentido uma disjunção, portanto, em relação à configuração externa do corpo e à imagem interna do eu. A supremacia do exterior em relação ao interior torna possível o entendimento do poder que a glorificação e exibição do corpo humano alcançaram na sociedade hodierna. A valorização da configuração externa do corpo pela sociedade de alguma forma se vincula ao modo como a publicidade, enquanto importante forma de comunicação para a sociedade hodierna, desenvolve as suas representações.

A publicidade é entendida como uma forma de comunicação que alimenta um ideal de beleza, ariano, com ênfase em corpos harmônicos, saudáveis e jovens conforme abordado por Safatle (2015) ao abordar o comentário do fotógrafo Oliviero Toscani, dos anos 80 do século passado. Da mesma forma, é questionada pelo fotógrafo a perspectiva falocêntrica de sexualidade que norteia as representações sociais presentes no conteúdo produzido. Mas no decorrer da década de 1990, já podia ser verificado o encaminhamento de um processo que reconfigurava as representações sociais veiculadas na mídia que tinham relação com o corpo e a sexualidade. Tal processou fez com que lentamente passassem a aparecer na mídia tipos de corpos e sexualidade, os quais até aquele momento não faziam parte do repertório de possibilidades para exposição nos anúncios publicitários. Foram campanhas produzidas pela Benetton, Calvin Klein, Versace e PlayStation, em que "corpos doentes, mortificados, des-idênticos, portadores de uma sexualidade ambígua, autodestrutiva e muitas vezes perversa marcaram a trajetória da publicidade nos anos 1990" (SAFATLE, 2015, p. 209).

$\mathrm{Na}$ atualidade, em alguns vídeos comerciais disponibilizados nos canais de empresas do YouTube pode ser observada a apresentação de corpos que fogem ao padrão hegemônico. Nos comerciais pesquisados, pode ser verificada a presença de corpos que não se enquadram no padrão de beleza hegemônico, ou seja, pessoas não magras, com tipos físicos variados, de diferentes etnias, de faixas etárias diversificadas, como também com uma sexualidade que não se enquadra no padrão heteronormativo, além 
de outras diferenças. Para observar, na publicidade, a apresentação de corpos que não se enquadram no padrão hegemônico, foram selecionados os seguintes comerciais da empresa de cosméticos Avon: Isso é pra mim, em que têm destaque, principalmente, pessoas que não são magras, sendo mostrada uma variedade de formatos de corpos; o comercial Attraction, que apresenta dois modelos cujo gênero é de difícil distinção. Além disso, foi selecionado o comercial da empresa de cosméticos Dove, denominado A beleza nos meus próprios termos, em que se destaca a variedade de tipos de corpos, com pessoas não magras e com faixa etária acima do que comumente é definido como jovem. Por fim, ainda, o comercial da marca de cerveja Skol, intitulado Skolors, cujo destaque são os corpos não magros, de diferentes cores e formas, além da presença de uma pessoa com vitiligo e, também, de pessoas albinas.

A apresentação de uma diversidade de corpos nos meios de comunicação é o desejo de várias pessoas e a publicidade atender a esse anseio, certamente para atingir aos seus interesses junto aos consumidores. Com pouca participação em relação ao padrão hegemônico, a diversidade de corpos possivelmente tenha relação com a forma como a sociedade valoriza o que considera ser o corpo ideal, pois temos que considerar que a publicidade é resultado também da cultura em que ela está inserida. Nesse sentido é importante considerar a publicidade em seus aspectos econômicos, sociais e culturais de modo a se buscar entender essa importante forma de comunicação.

\section{Considerações finais}

Neste artigo, procurou-se fazer uma abordagem da publicidade considerando três perspectivas: a primeira que observa o vínculo entre a publicidade e as relações de produção; a outra que pensa o consumo e a publicidade em uma perspectiva da ética; e a última que procura entender a publicidade pelo seu papel de colaborar na construção do imaginário contemporâneo, mais especificamente, no sentido de influenciar o engendramento das identidades e subjetividades dos sujeitos. Nesse aspecto, embora a publicidade tenha dado início a um processo de reelaboração das representações sociais nos comerciais, sua perspectiva tem se mantido em torno de um padrão hegemônico na representação do corpo. Contudo, entende-se que é relevante estudar essa reelaboração, embora lenta e com critérios, no sentido de tentar entender a lógica das representações do corpo na publicidade, para compreender que relação essa forma de comunicação estabelece com a cultura para se constituir desse modo.

\section{Referências}

AVON. Linha de Lingerie Avon Signature Apresenta: \#IssoEPraMim - Avon. 2017, (3 min 06 s). Disponível em: <https://www.youtube.com/watch?v=B8HIHaP73E8 >. Acesso em: 27 jun. 2018.

AVON. Avon attraction - nova fragrância - Avon. 2016, (1 min 03 s). Disponível em: <https:// www.youtube.com/watch?v=wCLkaXKYRBA>. Acesso em: 27 jun. 2018. 
BAUMAN, Zygmunt. Modernidade Líquida. Rio de Janeiro: Editora Zahar, 2001.

BAUDRILLARD, Jean. Significação da publicidade. In. LIMA, Luiz Costa. (Org.). Teoria da cultura de massa. 5. ed. São Paulo: Ed. Paz e Terra, 2000. p. 273-80.

BARBALHO, Alexandre. Cidadania, minorias e mídia: ou algumas postas ao liberalismo. In: PAIVA, Raquel; BARBALHO, Alexandre. (Org.) Comunicação e cultura das minorias. São Paulo: Paulus, 2009.

CASTELLS, Manuel. O poder da identidade. São Paulo: Paz e Terra. v. 2., 2001

CUCHE, Denys. A noção de cultura nas ciências sociais. Bauru: Edusc, 1999.

DOVE. Dove - A beleza nos meus próprios termos \#MinhaBelezaMinhaEscolha. 2016, (1 min 30 s). Disponível em: $<$ https://www.youtube.com/watch?v=3yNnWVgCJg8 $>$. Acesso em: 27 jun. 2018.

HALL, Stuart. A identidade cultural na pós-modernidade. Rio de Janeiro: DP\&A, 2001.

PIEDRAS, Elisa R. Fluxo Publicitário. Anúncios, produtores e receptores. Porto Alegre: Sulina, 2009.

ROCHA, Everardo P. Guimarães da. Magia e capitalismo. Um estudo antropológico da publicidade. São Paulo: Brasiliense, 1995.

SILVA, Tomaz Tadeu da. A produção social da identidade e da diferença. In: SILVA, Tomaz Tadeu da. (Org.); HALL, Stuart; WOODWARD, Kathryn. Identidade e diferença. A perspectiva dos estudos culturais. Petrópolis/RJ: Vozes, 2014.

SILVEIRINHA, Maria João. Democracia e reconhecimento: repensar o espaço público. In: PAIVA, Raquel; BARBALHO, Alexandre. (Org.) Comunicação e cultura das minorias. São Paulo: Paulus, 2009.

SAFATLE, Vladimir. O circuito dos afetos. São Paulo Cosac \& Naify, 2015.

SANTAELLA, Lúcia. Corpo e comunicação: sintoma da cultura. São Paulo: Paulus, 2004. SKOL. Skolors. 2017, (1 min 22 s). Disponível em:<https://www.youtube.com/watch?v=mQx_ VmCQu5w>. Acesso em: 27 jun. 2018.

TRINDADE, Eneus. Propaganda, identidade e discurso. Brasilidades midiáticas. Porto Alegre: Sulina, 2012.

WILLIAMS, Raymond. Cultura e materialismo. São Paulo: Editora UNESP, 2011.

WOODWARD, Kathryn. Identidade e diferença. Uma introdução teórica e conceitual. In: SILVA, Tomaz Tadeu da. (Org.); HALL, Stuart; WOODWARD, Kathryn. Identidade e diferença. A perspectiva dos estudos culturais. Petrópolis/RJ: Vozes, 2012. 


\title{
Three articulations of advertising with the social world
}

\begin{abstract}
This article considers advertising as an important form of communication for contemporary society and aims to reflect on it from three points of view, the first being the connection between advertising and production relations; the other, which analyzes consumption and advertising on the basis of ethics; and also the notion that seeks the understanding of advertising in its role of contributing to the construction of the contemporary imaginary, especially considering the aspect of suggesting the construction of the identities and subjectivities of the subjects. Already for some time, advertising has set in motion a process of recomposition of social representations in its campaigns, although in most commercial productions an approach based on a hegemonic pattern in the representation of the body remains. It is relevant to study this re-elaboration, to generate an understanding about the logic of representations of the body in advertising, seeking to understand the bonds created with the culture that collaborate so that advertising has this character.
\end{abstract}

\section{Keywords}

Advertising. Body. Identity. Culture. Subjectivity.

\section{Sobre os autores}

Marinês Andrea Kunz. Doutora em Letras, Mestre em Comunicação, Graduada em Letras Português/Alemão. Professora e Pesquisadora do PPPG em Processos e Manifestações Culturais, do Mestrado Profissional em Letras e do curso de Letras.

marinesak5@gmail.com

João Batista Nascimento dos Santos. Doutorando e Mestre em Comunicação e Informação (UFRGS), Graduado em Publicidade e Propaganda (UNISINOS). Publicitário autônomo. joaobnasc.santos@gmail.com 